SILVA, M.R. et al. Seleção de bovinos de corte através da técnica de ultrassonografia. PUBVET, Londrina, V. 5, N. 27, Ed. 174, Art. 1177, 2011.

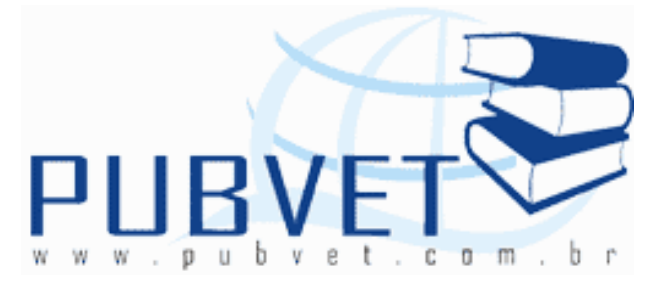

PUBVET, Publicações em Medicina Veterinária e Zootecnia.

\title{
Seleção de bovinos de corte através da técnica de ultrassonografia
}

Mérik Rocha Silva ${ }^{1}$, Edson Júnior Heitor de Paula², Cristiano da $\mathrm{Cruz}^{2}$, Karina Ferro Cervelati ${ }^{3}$, Marcelo da Silveira Meirelles Pinheiro ${ }^{2}$

${ }^{1}$ Autor: Zootecnista, Professor do Curso de Agropecuária da Faculdade de Pontes e Lacerda - FACIPEL; merikrocha@hotmail.com.

${ }^{2}$ Professores colaboradores: Zootecnistas, Mestres, Professores do Departamento de Zootecnia da UNEMAT, caixa postal 181, CEP 78250-000, Pontes e Lacerda-MT.

${ }^{3}$ Colaboradora: Zootecnista autônoma.

\section{Resumo}

Atualmente a pecuária de corte brasileira vive um bom momento comercial, consegue acesso a muitos mercados. Nosso país apresenta crescimento na produção de grãos e melhoria nas estruturas para exportação, ou seja, tudo vai bem. Mas, os pecuaristas devem evitar se acomodarem, e aproveitarem a estabilidade para melhorar seus produtos, incrementando tecnologia e qualidade na carne bovina. Este trabalho apresenta o resumo das informações importantes para a seleção animal a partir dos dados já obtidos através da técnica de ultrassonografia (US). Uma das formas de se realizar o aprimoramento do produto carne é promover melhoramento genético de bovinos de corte, nesse caso através da seleção dos bovinos para formação dos melhores rebanhos em relação as características de carcaça. Abordamos o 
SILVA, M.R. et al. Seleção de bovinos de corte através da técnica de ultrassonografia. PUBVET, Londrina, V. 5, N. 27, Ed. 174, Art. 1177, 2011.

volume da pecuária brasileira e local e seleção de bovinos: correlações genéticas, herdabilidades e rendimento de carcaça.

Termos para indexação: ultrassonografia de carcaça, seleção animal, herdabilidades.

\title{
Selection of beef cattle through the technique of ultrasonography
}

\begin{abstract}
Currently, the Brazilian beef cattle industry is experiencing a good time shopping, get access to many markets. Our country has growth in grain production and improvement in export structures, ie, everything goes well. However, farmers should avoid to accommodate and take advantage of the stability to improve their products, improving technology and quality in beef. This paper presents a summary of important information for selecting animals from the data already obtained by the technique of ultrasonography (U.S.). One way to accomplish the improvement of meat product is to promote genetic improvement of beef cattle in this case through the selection of the best training for cattle herds over the carcass traits. We approached the volume of Brazilian livestock and local selection in cattle: genetic correlations, heritabilities and carcass yield.
\end{abstract}

Index Terms: ultrasound carcass, animal selection, heritability.

\section{INTRODUÇÃO}

A pecuária de corte é uma atividade de fundamental importância para o Brasil e principalmente para o Estado de Mato Grosso que é eminentemente agrário. De acordo com Cardoso (2010) o rebanho brasileiro atual é de 197 milhões de cabeças, podendo chegar a 198,9 milhões em dezembro de 2010. Neste cenário de crescimento contínuo o rebanho mato-grossense é o principal contribuinte dos números nacionais, o estado terminou o ano de 2009 com o maior rebanho de bovinos do país, são 27 milhões de cabeças, 5\% a mais que 
SILVA, M.R. et al. Seleção de bovinos de corte através da técnica de ultrassonografia. PUBVET, Londrina, V. 5, N. 27, Ed. 174, Art. 1177, 2011.

o rebanho de 2008 (ACRIMAT, 2010; TARDIM, 2010 e TOMAZ, 2010). Segundo o IBGE (2010) os frigoríficos lotados em Mato Grosso abateram 3.996.941 cabeças de bovinos durante o ano de 2009, totalizando 993 toneladas de carcaça, superando a produção de toneladas de carcaças de frango e suínos. Segundo FAMATO (2008) o município de Pontes e Lacerda especificamente, tinha um rebanho de 620.301 animais no ano 2006.

As projeções revelam crescimentos do número de habitantes no mundo com aumentos no consumo per capita de alimentos, estima-se que ocorra uma necessidade de duplicar a produção de alimentos para atender a futura demanda mundial (PRODUTOR RURAL, 2010). Este futuro aumento na demanda cria a oportunidade do bovinocultor brasileiro crescer através do melhoramento genético para aumentar a produção dos animais que alimentarão o mundo, e trará a lucratividade almejada pelos pecuaristas (DIBIASI, 2006).

A ultrassonografia (US) pode ser resumida como uma técnica rápida e eficaz que proporciona alta confiabilidade de seus dados, que garante economia no processo produtivo na maioria dos casos, podendo ser utilizada para o melhoramento genético dos animais, proporcionando melhor produtividade ao pecuarista (SUGUISAWA, 2002). Entre os diferentes sistemas de produção a US poderia ser utilizada para determinar o ponto ideal de abate dos animais, evitando a deposição excessiva de gordura subcutânea que decorre com consumo superior de alimentos, aumentando o custo, sem melhorar a qualidade.

Objetivou-se com este estudo abordar a técnica de ultrassonografia como ferramenta para o melhoramento genético das características de carcaça dos bovinos destinados à produção de carne. Foi pontuado as informações acerca da deposição de gordura, considerando suas correlações com outras características, ressaltando a importância do rendimento de carcaça, bem como, o uso da seleção dos animais a partir dos dados do ultrassom. 
SILVA, M.R. et al. Seleção de bovinos de corte através da técnica de ultrassonografia. PUBVET, Londrina, V. 5, N. 27, Ed. 174, Art. 1177, 2011.

\section{REVISÃO BIBLIOGRÁFICA}

O melhoramento genético das características de carcaça de bovinos é precedido de definição das características desejáveis, a partir desta parametrização, realiza-se o estudo destas características (VENERONI, 2007). Para Figueiredo (2001) os métodos convencionais através do teste de progênie impreterivelmente exigem o abate das crias, demandam tempo e a coleta dos dados em frigoríficos exige cooperação deste, além de ser susceptível a erros difíceis de serem detectados.

A partir do propósito de avaliar os animais ainda vivos teríamos apenas três opções, os escores corporais, que devido ser realizado visualmente através de técnico treinado, apresenta insuficiente nível de confiabilidade. A ressonância magnética apresenta exatidão nas mensurações, mas é extremamente onerosa, e praticamente impossível de ser utilizada a nível de campo; resultando como opção a técnica da ultrassonografia (US), que apresenta simplicidade e boa confiabilidade além de uma incrível praticidade de locomoção (FIGUEIREDO, 2001), aliando rapidez da análise e boa acurácia (VENERONI, 2007).

\subsection{MERCADO DA CARNE BOVINA}

O Brasil tem se apresentado como um grande vendedor de carne bovina, após o aumento de $20 \%$ na produção nacional foi constatado a quadruplicação nas exportações de carne in natura (LUCHIARI FILHO, 2006). No entanto, o país não acumula grandes rendimentos com a venda desta commodity, em decorrência dos mercados que supre; o fator principal desta desproporção vendas/receitas é decorrente da baixa qualidade dos produtos brasileiros (BONIN, 2008 e LUCHIARI FILHO, 2006). As deficiências são principalmente na padronização em relação a peso, idade e grau de acabamento (LUCHIARI FILHO, 2006). 
SILVA, M.R. et al. Seleção de bovinos de corte através da técnica de ultrassonografia. PUBVET, Londrina, V. 5, N. 27, Ed. 174, Art. 1177, 2011.

O valor que o pecuarista obterá com a venda dos animais define os investimentos que o bovinocultor irá empregar na criação, ou seja, o grau de tecnologia produtiva utilizada depende do possivél retorno financeiro, vinculando a produção ao valor de venda da carne bovina. Atualmente o mercado consumidor imprime ao pecuarista as características que o produto deverá apresentar para suprir seus anseios, esta demanda é formada por diversos mercados, alguns exigentes em qualidade, outros almejam produtos com preço inferior (YOKOO, 2009).

Em relação ao percentual de gordura, a carcaça animal ideal tem características diferentes para cada consumidor, alguns buscam se alimentar de carne com muita gordura de marmoreio; que apresentem deposição de gordura intramuscular de 8 e 12\%, são respectivamente os consumidores americanos e japoneses (YOKOO, 2009); do outro lado ha diversos consumidores que preferem carnes mais saudáveis, visando reduzir a gordura animal de suas dietas, em geral os consumidores europeus.

\subsection{SELEÇÃO DOS ANIMAIS}

Segundo Magnabosco et al. (2006) as características de desenvolvimento ponderal reproduzem informações insuficientes para desenvolvermos um programa de melhoramento genético, pois, o peso total não representa a quantidade exata de parte comestível dos animais. As novas demandas de mercado são de carcaças uniformes, com boa cobertura de gordura e marmorização, repercutindo em carnes de melhor qualidade (MAGNABOSCO et al., 2006 e IMA, 2010).

A bovinocultura de corte brasileira produz muito em volume, mas pouco em qualidade, devido a deficiente pressão de seleção dos bovinos genéticamente superiores para características qualitativas de carcaça (BONIN, 2008). No caso de se promover um melhoramento genético de características de carcaça deve-se seguir critérios específicos na avaliação de cada raça, 
SILVA, M.R. et al. Seleção de bovinos de corte através da técnica de ultrassonografia. PUBVET, Londrina, V. 5, N. 27, Ed. 174, Art. 1177, 2011.

devido haver variação nas características fisiológicas e genéticas entre os animais (AVAL, 2010) .

Durante a seleção de animais deve se atentar para a correlação que há na maior frequência de determinada característica poder prejudicar outra característica do rebanho que esteja em bons níveis, é o caso da seleção para animais mais eficientes reprodutivamente que ocasionalmente repercute em decrescimo do mérito genético dos animais para características produtivas (DIBIASE, 2006). No caso da ultrassonografia (US) Yokoo (2009) conclui que a deposição de gordura subcutânea (característica produtiva) não é prejudicada pela seleção para menor idade ao primeiro parto em fêmeas Nelore (característica reprodutiva).

A idade das matrizes interfere sob a cria em relação ao desenvolvimento da gordura subcutanea na EG e EGP8. Yokoo et al. (2005) avaliando as crias com idade entre 470 e 590 dias, tendo como variação a idade de suas mães, verificou que as progenitoras mais jovens, com idade de 23 meses, conceberam animais com EG e EGP8 maiores que crias de bovinos com mais de 162 meses (13 anos) de idade na ocasião do parto.

Além da idade da reprodutora existe variação entre animais da mesma raça. Para Magnabosco et al. (2006) as características de carcaça têm alta variabilidade na raça Nelore, o que possibilita rápidos e evidentes resultados sobre seleção de animais superiores para características de carcaça, favorecendo a seleção desta que é uma das mais difundidas raças de bovinos de corte do Brasil. A questão é que a carne dos zebuínos mesmo quando abatidos antecipadamente e com suficiente cobertura de gordura, não produzem carne com maciez aceitável, sendo citados por diversas literaturas como animais que apresentam carne dura quando puramente zebuínos, assim como animais com maior composição de genética zebuína apresentam menor maciez em relação a animais com maior proporção de genética taurina, mesmo estando em estágios similares de deposição de gordura subcutânea (MAGNABOSCO et al., 2006). 
SILVA, M.R. et al. Seleção de bovinos de corte através da técnica de ultrassonografia. PUBVET, Londrina, V. 5, N. 27, Ed. 174, Art. 1177, 2011.

Sainz (2004) expõe que as calpaínas são responsavéis pela hidrólise do conteúdo celular após o abate do animal, estas enzimas são naturalmente dispostas no músculo e outros tecidos do animal vivo, onde, após o abate do animal estas realizam com auxilio do cálcio a maturação da carne, tornando-a mais macia. Magnabosco et al. (2006) expõe que a calpastatina que inibe a ação da calpaína no processo de proteólise post-mortem é encontrada em maiores concentrações em zebuinos em relação aos taurinos.

Esta diferença fisiológica que é de origem genética nos animais Bos taurus indicus repercute em cortes de carne dura em relação aos taurinos. Em experimento com animais oriundos de cruzamento Nelore $x$ Angus Magnabosco et al. (2006) afirma que estes animais apresentaram maior $A O L$, maior grau de acabamento e mais gordura subcutânea (EG e EGP8) resultando em carnes com grau de maciez superior em relação aos animais zebuínos puros.

Para Magnabosco et al. (2006) historicamente a carne de animais cruzados Angus $X$ Nelore apresentam carcaças mais pesadas e melhor terminadas em relação a animais Nelore. Além dos animais zebuínos apresentarem carne em menor grau de marmoreio e menor maciez em relação aos taurinos. As características de carcaça AOL, EG e P8, mensuradas por ultrassom apresentam suficiente variabilidade para justificar a realização de programas de melhoramento genético.

Magnabosco et al. (2006) identificou que machos castrados tem em média duas arrobas a mais no peso da carcaça, refletindo em maior área de olho de lombo; no entanto, as fêmeas apresentam melhor acabamento da gordura subcutânea em relação aos machos castrados, tanto na avaliação visual quanto a EGP8; além das carcaças das novilhas apresentarem melhor pH pós-mortem.

\subsubsection{Correlações Genéticas}

A partir dos dados obtidos por Yokoo (2009) destaca-se não haver correlação genética negativa entre as CCUS (Características de Carcaça Obtidas por Ultrassom) e as características reprodutivas: perímetro escrotal ao 
SILVA, M.R. et al. Seleção de bovinos de corte através da técnica de ultrassonografia. PUBVET, Londrina, V. 5, N. 27, Ed. 174, Art. 1177, 2011.

sobreano (PE450), peso com doze e dezoito meses e intervalo entre partos (IPP). Para Lobo et al. (2010) diversas pesquisas realizadas por melhoristas demostram que a seleção de animais preconizando os bovinos mais precoces sexualmente resulta também na seleção de animais com precocidade de acabamento; ou seja, a seleção de animais a partir de características de carcaça contribui para seleção de animais mais precoces reprodutivamente.

Lobo et al. (2010) e IMA (2010) expõem que há uma alta correlação genética de precocidade sexual e tendência a antecipar a deposição de gordura sobre a carcaça (EG), em média cada $\mathrm{mm}$ de gordura subcutânea favorece em $12 \%$ de probabilidade de novilhas apresentarem prenhez. Para Costa Filho (2009) o aumento da EG eleva a probabilidade de prenhez em novilhas Nelore criadas no Estado do Mato Grosso do Sul; conforme Figura 1, novilhas com EG de $6 \mathrm{~mm}$ apresentam $60 \%$ de chance de emprenhar. A diferença no percentual de prenhez entre os animais com escore inferior a $6 \mathrm{~mm}$ é insignificativo.

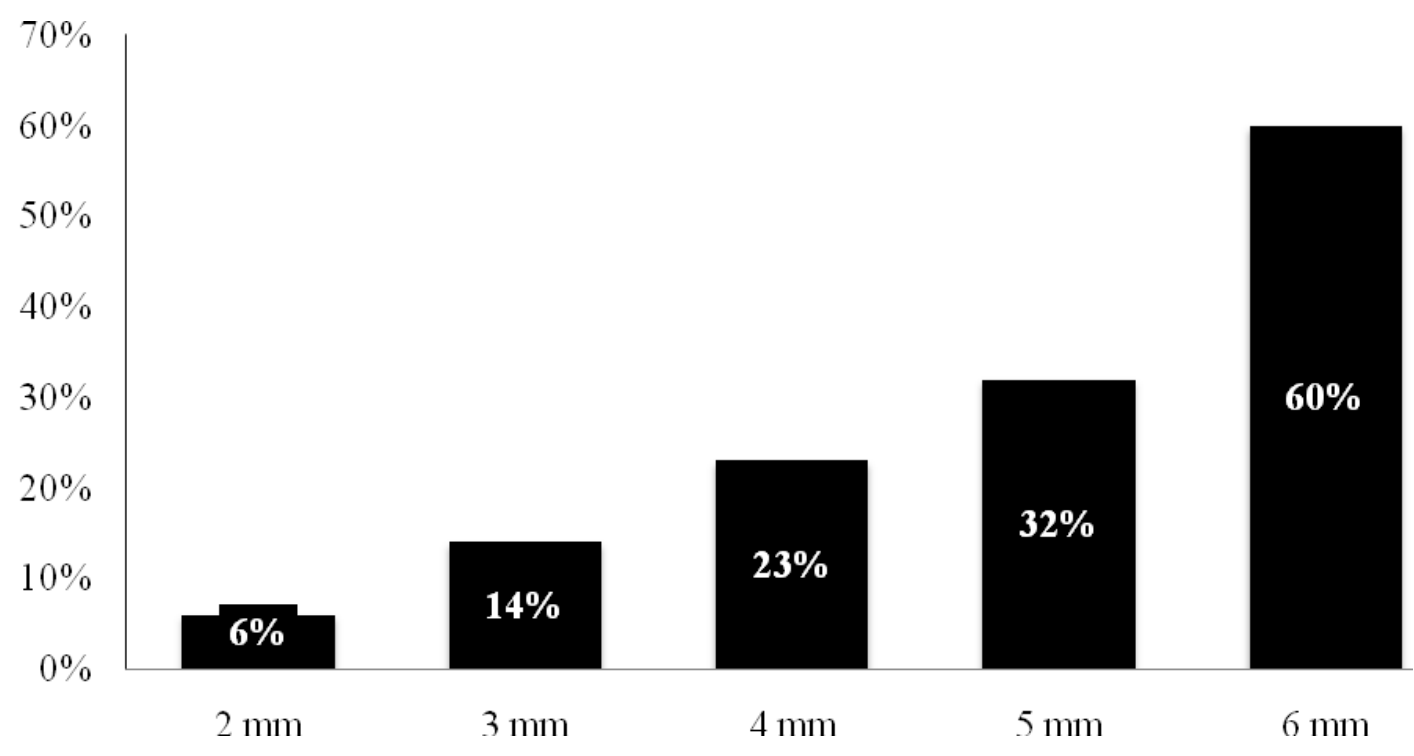

Figura 1. Probabilidade de prenhez em diferentes classes de espessura de gordura subcutânea média. Adaptado de Costa Filho, 2009. 
SILVA, M.R. et al. Seleção de bovinos de corte através da técnica de ultrassonografia. PUBVET, Londrina, V. 5, N. 27, Ed. 174, Art. 1177, 2011.

Segundo IMA (2010) durante a seleção de animais o produtor deve estar atento a correlações entre características, ao selecionar animais superiores para melhorar seu rebanho em uma característica, este poderá estar prejudicando ou favorecendo outra característica. Existe uma correlação genética positiva entre deposição de gordura e precocidade sexual como já mencionado, no entanto, existe uma correlação negativa com a altura do animal. Yokoo (2009) identificou correlação genética negativas entre a altura do posterior e a EG. Ou seja, animais maiores são tardios em relação a precocidade sexual e deposição de gordura.

\subsubsection{Herdabilidades}

As características de carcaça são transmitidas de progenitores para progênies, mas, além das informações genéticas o meio onde a progênie é criada interfere sobre o desenvolvimento das características de carcaça. Portanto, além das características genéticas existem variantes como alimentação e clima que interferem no desenvolvimento do animal, no entanto nenhuma característica do ambiente pode alterar o genoma da progênie. $O$ melhoramento genético dos animais é baseado na seleção a partir de suas características genéticas. Estas características não são avaliáveis senão através de mensurações ponderáveis ou fenotípicas dos animais, como as AOL, EG e EGP8 obtidos através da ultrassonografia. No entanto, há variações no nível de transferência de informação genética que os progenitores transmitem às suas crias para cada característica, ou seja, as crias possivelmente não são idênticas aos pais, sendo na realidade transmitido do reprodutor e da matriz as características em níveis e intensidade diferentes às crias, as variações da itensidade de transmisão de cada característica para a cria é definido pela herdabilidade $\left(\mathrm{h}^{2}\right)$ da característica. Sendo assim, a herdabilidade varia de cada característica, no caso da AOL sua herdabilidade pode variar de 0,27 a 0,46 (Tabela 1), dependendo do ambiente e idade dos animais (PEREIRA, 2008). 
SILVA, M.R. et al. Seleção de bovinos de corte através da técnica de ultrassonografia. PUBVET, Londrina, V. 5, N. 27, Ed. 174, Art. 1177, 2011.

Como a $\mathrm{h}^{2}$ representa a fração das características transmitidas às progênies, esta acaba representanto a variação das características decorrentes do genoma animal. Pereira (2008) classifica as $\mathrm{h}^{2}$ de acordo com sua intensidade, sendo de 0,0 a 0,01 baixa $h^{2}$; de 0,1 a 0,3 herdabilidades médias e acima de $0,3 \mathrm{~h}^{2}$ alta.

Tabela 1. Herdabilidades da Área de Olho de Lombo (AOL).

\section{Autor}

\begin{tabular}{lc} 
& $\mathbf{h}^{\mathbf{2}}$ encontrada \\
\hline Barbosa, 2005 & 0,64 \\
Bonin, 2008 & 0,27 \\
Magnabosco, 2009 & 0,41 \\
Yokoo, 2009 & $0,46^{1}$ \\
Yokoo, 2009 & $0,33^{2}$ \\
${ }^{1}$ progênies com um ano; ${ }^{2}$ progênies ao sobreano.
\end{tabular}

A herdabilidade $\left(h^{2}\right)$ média da medida de EG é de 0,408 (Tabela 2); potencializando o uso da seleção dos reprodutores e matrizes com adequada EG, a fim de, possibilitar maior freqüência de crias no rebanho com EG superior, inserindo esta característica desejável nas futuras progênies através do efeito aditivo dos genes (PEREIRA, 2008).

As três principais características de carcaça mensuráveis por ultrassonografia apresentam herdabilidades altas (Tabelas 1, 2 e 3). Representando que a variação das características de AOL, EG e EGP8 é de origem genética, justificando o uso da observação destas características para a seleção de progenitores para formação de rebanhos de animais superiores em relação as características de carcaça (IMA, 2010 e PEREIRA, 2008) 
SILVA, M.R. et al. Seleção de bovinos de corte através da técnica de ultrassonografia.

PUBVET, Londrina, V. 5, N. 27, Ed. 174, Art. 1177, 2011.

Tabela 2. Herdabilidades $\left(\mathrm{h}^{2}\right)$ da espessura da gordura de cobertura (EG).

\begin{tabular}{lc}
\hline \multicolumn{1}{c}{ Autor } & $\mathbf{h}^{2}$ encontrada \\
\hline Barbosa, 2005 & 0,41 \\
Lobo et al., 2010 & 0,35 \\
Magnabosco, 2009 & 0,41 \\
Pereira, 2008 & 0,35 \\
Sainz et al., 2003 & 0,37 \\
Yokoo, 2009 & $0,42^{1}$ \\
Yokoo, 2009 & $0,59^{2}$ \\
\hline${ }^{1}$ progênies com um ano; ${ }^{2}$ progênies ao sobreano. &
\end{tabular}

Tabela 3. Herdabilidade da espessura da gordura de cobertura na garupa (EGP8).

\begin{tabular}{lc}
\hline \multicolumn{1}{c}{ Autor } & $\mathbf{h}^{2}$ encontrada \\
\hline Magnabosco, 2009 & 0,65 \\
Yokoo, 2009 & $0,60^{1}$ \\
Yokoo, 2009 & $0,55^{2}$ \\
\hline${ }^{1}$ progênies com um ano; ${ }^{2}$ progênies ao sobreano. &
\end{tabular}

Geneticamente temos diversos genes que foram identificados como possíveis responsáveis pela deposição de gordura subcutânea (EG) nos bovinos destinados a produção de carne, entre eles o DGAT1, FABP3, GH1, LEP e TG; no entanto, a exata influência de cada gene sobre esta característica não foi confirmada (FREITAS et al., 2009).

\subsubsection{Rendimentos de Carcaça}

Há dois fatores de avaliação importantes na classificação de carcaças: musculosidade e deposição de gordura subcutânea. Entre estes fatores há uma correlação genética que permite-nos selecionar animais com boa gordura de 
SILVA, M.R. et al. Seleção de bovinos de corte através da técnica de ultrassonografia. PUBVET, Londrina, V. 5, N. 27, Ed. 174, Art. 1177, 2011.

cobertura, simultaneamente selecionando animais com maior rendimento de carcaça (MAGNABOSCO et al., 2006).

Aproximadamente $54 \%$ do peso vivo do animal pesado na propriedade, comporá o peso da carcaça e vísceras comestíveis. Este percentual de aproveitamento comercial varia entre animais em decorrência das diferentes raças, sexo, idade, sistema de matança e de engorda (GOMIDE, RAMOS e FONTES, 2006). A seleção por progenitores com maiores AOL, resulta na formação de rebanhos de animais capazes de promover aumento na produção de carne por animal (IMA, 2010 e MORAIS, 2007). Portanto a medida de AOL têm relação positiva com o rendimento de carcaça, principalmente nos cortes nobres (SAINZ, 2009), devido o músculo Longissimus dorsi apresentar correlação com rendimento de carcaça e com a porção comestível, podendo ser utilizado como indicador de musculosidade e acabamento de toda carcaça (MAGNABOSCO et al., 2006). Este é o músculo que compõe a AOL, que é mensurada através da ultrassonografia (SAINZ, 2009).

A empresa Conexão Delta $G$ baseia-se na AOL para selecionar animais com carcaças maiores e com maior rendimento dos cortes comerciais em relação ao peso vivo do animal. Os dados de EG identificam ao sobreano os animais com maior facilidade de terminação (GENESYS, [S.d.]). A Associação Nacional de Criadores e Pesquisadores (ANCP) realiza avaliação genética de bovinos apartir de suas características de carcaça ha sete anos; chegando a desenvolver uma DEP (Diferença Esperada na Progênie) nomeada DACAB que é mensurada a partir de dados obtidos através de avaliações de EG, utilizadas para estimar a precocidade animal em relação a terminação (LOBO et al., 2010).

\section{CONSIDERAÇÕES FINAIS}

O pecuarista deve realizar o melhoramento genético do seu rebanho utilizando a técnica da ultrassonografia para garantir o mais breve possível a produção regular de animais com boa gordura subcutânea e superior 
SILVA, M.R. et al. Seleção de bovinos de corte através da técnica de ultrassonografia. PUBVET, Londrina, V. 5, N. 27, Ed. 174, Art. 1177, 2011.

rendimento de carcaça, a partir de então o produtor terá o produto requerido pelas grandes redes frigoríficas, alcançando maior poder de negociação, vendendo seus animais para o melhor comprador.

\section{REFERÊNCIAS CITADAS}

ACRIMAT (A) - Associação dos Criadores de Mato Grosso. Rebanho Bovino em MT tem alta de 5\% em 2009. Cuiabá, 26 jan 2010. Disponível em: <http://www.acrimat. org.br/novosite/noticias/1131>. Acesso em: 12 fev 2010.

AVAL Serviços Tecnológicos S/C. Protocolo para avaliação de carcaça. Uberaba, [S.d.]. Disponível em: <http://www.aval-online.com.br/>. Acesso em: 02 fev 2010.

BARBOSA, V. Inferência bayesiana no estudo genético quantitativo de características de carcaça, utilizando a técnica de ultra-sonografia e suas relações com crescimento, em novilhos da raça Nelore. 2005. Dissertação (Mestrado em Zootecnia, área de concentração Produção Animal). Escola de Veterinária, Universidade Federal de Goiás. 2005. $81 \mathrm{p}$.

BONIN, M.N. Estudo da influência de touro e de genearca da raça Nelore nos aspectos quantitativos de carcaça e da carne. Dissertação (Mestre em Zootecnia). 2008. 157 p. Faculdade de Zootecnia e Engenharia de Alimentos da Universidade de São Paulo. Pirassunuga. 2008.

CARDOSO, D. Arroba em baixa frusta as expectativas: Analistas prevêem que o preço vai oscilar abaixo de $\mathrm{R} \$ 90,00$ ao longo de todo o ano. Anuário DBO: Os números da pecuária. São Paulo. n.351. p.20, janeiro 2010.

COSTA FILHO, L.C.C. Efeito das características de carcaça e peso vivo sobre a taxa de prenhez de novilhas Nelore precoce no estado do MS. In Reunião Anual da Sociedade Brasileira de Zootecnia. 46. 2009. Anais. Maringá: Universidade Estadual de Maringá, 2009.

DIBIASI, N.F. Estudo do crescimento, avaliação visual, medidas por ultrassonografia e precocidade sexual em touros jovens pertencentes a vinte e uma raças com aptidão para corte. Jaboticabal, 2006. UNESP - Universidade Estadual Paulista "Julio de Mesquita Filho", Faculdade de Ciencias Agrarias e Veterinarias, 2006. p.94

FAMATO - Federação da Agricultura e Pecuária do Estado de Mato Grosso. Diagnóstico da cadeia produtiva agroindustrial da bovinocultura de corte do Estado de Mato Grosso. Cuiabá: KCM, 2008. 408 p.

FIGUEIREDO, L.G.G. Estimativa de parâmetros genéticos de características de carcaça feitas por ultra-sonografia em bovinos da raça Nelore. Pirrassunuga, 2001. Dissertação (Mestrado em Zootecnia). Faculdade de Zootecnia e Engenharia de Alimentos, Universidade de São Paulo. 2001, 52 p.

FREITAS, C.O.M. et al. Frequências alélicas e genotípicas do polimorfismo TG/MBOI em bovinos de diferentes grupos genéticos. Congresso Brasileiro de Genética. 55, 2009. Anais. Águas de Lindóia: Centro de Convenções do Hotel Monte Real Resort. p.195. 
GENESYS - Consultores Associados S/C Ltda. Características avaliadas. Porto Alegre, 2010. Disponível em:<http://www.gensys.com.br/home /win_sumarios.php?id_sumario= 36\&id=958\& $>$. Acesso em 11 jun 2010.

GOMIDE, L.A.M., RAMOS, E.M. e FONTES, P.R. Tecnologia de abate e tipificação de carcaças. Viçosa: Editora UFV, 2006. 370 p.

IBGE - Instituto Brasileiro de Geografia e Estatística. Indicadores IBGE: Estatística da produção pecuária. [s.I.]:2010. 29p.

IMA - Instituto Mineiro de Agropecuária. Seleção por ultra-sonografia de carcaça melhora rendimento frigorífico: A baixa remuneração da carne bovina no Brasil ainda é um problema freqüente. Clipping eletrônico. Belo Horizonte, 11 abr 2010.

LOBO, R.B. et al. Medidas por ultrassonografia. In Avaliação genética de touros das raças Nelore, Guzerá, Brahman e Tabapuã: Sumário 2010, ANCP. Ribeirão Preto: Associação Nacional dos Criador. e Pesquisadores, 2010. 172 p.

LUCHIARI FILHO, A. Produção de carne bovina no Brasil qualidade, quantidade ou ambas ? Simpósio sobre desafios e novas tecnologias na bovinocultura de corte (SIMBOI), II, Anais. Brasília, 2006. 10 p.

MAGNABOSCO, C.U. et al. Avaliação genética e critérios de seleção para características de carcaça em zebuínos: relevância econômica para mercados globalizados. Disponível em http://www.aval-online.com.br/ artigostecnicos/artigos/trabalho_SimCorte_2006_16_05_definitivo.pdf>. Acesso em 08 jan 2010. [S.I.], 2006.

MAGNABOSCO, C.U. Tecnologias em melhoramento genético de zebuínos. In Simpósio de Melhoramento Animal do Vale do Guaporé - MT, I, Palestra (slides). Pontes e Lacerda, out 2009.

MORAIS, L. Gordura sob medida: Exame de ultra-som para bovinos ganha adeptos na pecuária nacional. Revista DinheiroRural de junho/2007. Disponivél em:<http://www.terra.com.br/revistadinheirorural/edicoes/32/artigo52649-1.htm> Acessado em 10 de junho de 2010.

PEREIRA, J.C.C. Melhoramento genético aplicado à produção animal. 5 ed. Belo Horizonte: FEPMVZ Editora, 2008. 617 p.

PRODUTOR RURAL, Revista. Boi ao quadrado. Cuiabá, n.199, ano 17, p. 40. Fevereiro/2010.

SAINZ, R.D. e ARAUJO, F.R.C. Uso de tecnologias de ultra-som no melhoramento do produto final carne. In Congresso Brasileiro de Raças Zebuínas, 5, 2002, Uberaba. Anais. Uberaba: 2002.

SAINZ, R.D. et al. Melhoramento genético da carcaça em gado zebuíno. In Seminário da Associação Nacional de Criadores e Pesquisadores, 11. Anais. Ribeirão Preto, 2003. 14 p.

SAINZ, R.D. Utilização do ultrassom no melhoramento de carcaças de bovinos de corte. In Simpósio de Melhoramento Animal do Vale do Guaporé - MT, I, Palestra (slides). Pontes e Lacerda, out 2009.

SUGUISAWA, L. Ultra-sonografia para predição das características e composição da carcaça de bovinos. Piracicaba, 2002. Dissertação. Escola Sup. de Agricultura "Luiz de Queiroz", Universidade de São Paulo. 2002, 70 p. 
TARDIM, C. O rebanho aumentou: o aumento deve-se à redução de abate de fêmeas; bezerro passou a ser bom negócio. Produtor Rural, Cuiabá, n.199, ano 17, p. 39. Fevereiro/2010.

TOMAZ, W. Encontro discute desafios da produção pecuária. Caderno Terra \& Criação do Jornal A Gazeta. Cuiabá, 03 mai 2010, edição n.6731.

VENERONI, G.B. Associação da região centromérica do cromossomo $14 \mathrm{com}$ espessura de gordura em bovinos da raça canchim. 2007. Dissertação (Mestrado em Genética e Evolução). Centro de Ciências Biológicas e da Saúde, Universidade Federal de São Carlos. 2007. $68 \mathrm{p}$.

YOKOO, M.J.I. Análise Bayesiana da área de olho do lombo e da espessura de gordura obtidas por ultrassom e suas associações com outras características de importância econômica na raça Nelore. 2009. Tese (Doutorado em Genética e Melhoramento Animal) Faculdade de Ciências Agrárias e Veterinárias, Universidade Estadual Paulista "Julio de Mesquita Filho", Jaboticabal, 2009.

YOKOO, M.J.I. et al. Fatores genéticos e ambientais que afetam as características da área de olho de lombo e a espessura de gordura medidas por Ultra-sonografia em bovinos da raça nelore ("Bos Indicus"). $42^{a}$ Reunião Anual da Sociedade Brasileira de Zootecnia, 25 a 28 de julho de 2005. Goiânia-GO. 